\title{
Experimental Analysis In Vapour Compression Refrigeration Using R22, R407A, HC Refrigerant
}

\author{
K Bharathi Raja1, A Arul Vinish², S Anatha Geethan ${ }^{3}$, G Jasper ${ }^{4}$ \\ and $\mathbf{G}$ Monish ${ }^{5}$
}

\author{
1,2,3,4,5 Department of Mechanical, Loyola Institute of Technology, \\ Chennai, Tamil Nadu, India
}

\begin{abstract}
The use of refrigerant mixtures has been a topic of current research in view of the concerns related to global warming and Ozone depletion problems caused by CFCs and HFCs. The HC mixture as an alternate refrigerant has been reported to be a promising one in addressing the global warming and Ozone depletion problems. In the present work an experimental set-up is built up to test Vapour Compression Refrigeration (VCR) system with different refrigerants. The aim of this work is to investigate the performance analysis of Vapour Compression Refrigeration system with alternate refrigerants such as Hydrocarbon (HC) refrigerants mixture and compare with Hydro Fluoro Carbon (HFC). The refrigeration system variables considered for the investigation of performance are evapourating temperature, condensing temperature and power consumption. The HC refrigerant mixture is observed to give superior performance compared to HFC refrigerant in terms of global level.
\end{abstract}

Keywords: Refrigeration, Refrigerant, Ozone depletion, Global warming, Vapour.

\section{Introduction}

The Refrigeration is the removal of heat from a material or space, so that its temperature is lower than that of its surroundings. When refrigerant absorbs the unwanted heat, this raises the refrigerant's temperature so that it changes from a liquid to a gas it evapourates. Refrigeration is a process that removes heat from a space, substance, or system to lower and/or maintain its temperature below the ambient temperature. In other words, refrigeration is artificial cooling. Energy in the form of heat is removed from a low-temperature reservoir and transferred to a high-temperature reservoir. The evapourator transfers heat into the refrigerant; the refrigerant transfers this heat to the condenser; the condenser transfers the heat to a cooling medium. Conduction is the flow of heat through a substance by contact of particles. The project aims critical comparative analysis of three different refrigerants closed after industrial surveys. The study of different refrigerant will reveal the comparison of factors which are directly related to the performance parameters and environmental factors. all the components compressor, condenser, evapourator and expansion devices have been studied for minimizing electricity consumption enhancing coefficient of performance of refrigeration cycle. At the end this study, we will be presenting a refrigeration cycle with enhanced performance and least environmental hazards as per international standards. There are 4 main components in the mechanical refrigeration system. Any components beyond these basic four are called accessories. The compressor is a vapour compression pump which uses piston are some other. method to compress the refrigerant gas and send it on its way to the condenser. The condenser is a heat exchanger which removes heat from the hot compressed gas and allows it to contents into a liquid. The liquid refrigerant is then routed to the metering device. This device restricts the flow by forcing the refrigerant to go through a small hole which cases a pressure drop. The component where the evapouration. takes is called the evapourator. The refrigerant vapour is then routed back to the compressor to the complete the cycle. After detailed study and industrial surveys, we were able to select following extensively used refrigerants and for domestic purpose: R22, R407A, HC

\section{Review of Literature}

$\mathrm{Li} \& \mathrm{Su}$ (2005) have reported the use of zero ODP and low GWP propane as refrigerants due to the refrigerating properties of it closely resembling to 
those of R22, thus making R290 a proposing alternative to R22 with the caution of its flammability.

Swinney et al (2001) have suggested that the binary mixtures (zeotropic or non-azeotropic) of hydrocarbons can also be used in the hybrid absorption - compression refrigeration cycle. The performance of this system is mainly based on volatility or fractional vaporization.

Fernando et al (2008) have predicted the heat transfer coefficients of condensers using propane as refrigerant was found to increase in the sub-cooling section with large uncertainty

Chang et al (2008) studied and predicted the energy saving potential of household refrigerator/freezer with variable frequency brushless DC compressor. They found that the energy saving of $35 \%$ using refrigerants HC R600a and HFC134a.

Bobbo et al (2004) gave the solution as HCs+HFCs blends which can be used as refrigerants with low GWP and ODP. Mixtures with R290 have acceptable COP and volumetric refrigerating effect only at relatively high mass fraction of propane. They have suggested the use of these mixtures due to the reduction in GWP without considering the elimination of flammability.

McLinden et al (2000) suggested that halocarbon refrigerants, propane, ammonia, carbon dioxide, R11, R12, R13, R22, R23, R114, R115, R125, R142b, $\mathrm{R} 143 \mathrm{a}$ as well as mixtures of these fluids have an average absolute deviations between the calculated and experimental values of thermal conductivity that are arranged from 1.08 to $5.57 \%$ for the pure fluids and 2.98 to $9.40 \%$ deviations for the mixtures given below R125/R134a, R32/propane, R32/R134a, propane/R134a, R32/R125 and R32/R125/R134a.

Comakli et al (2009) observed that the most effective parameters were the condenser air inlet temperature for COP and exergetic efficiency for the heat pump with the use of mixture of R404A / R22 and found the parameters were not influenced by R404A. They also suggested that the pure R22 will be the only solution for heat pump application.

\section{Experimental Setup}

This section provides a description of the facilities developed for conducting experimental work on a domestic refrigerator. The technique of charging and evacuation of the system is also discussed hereThe schematic diagram of the test unit and apparatus is shown in the Fig. The temperature of the refrigerant inlet/outlet of each component of the refrigerator was measured with copper-constantan thermocouples ( $\mathrm{T}$ type). The thermocouple sensors fitted at inlet and outlet of the compressor, condenser, and evapourator are shown in fig. Thermocouples/Temperature sensors were interfaced with a HP data logger via a PC through the GPIB cable for data storage.
Temperature measurement is necessary to find out the enthalpy in and out of each component of the system to investigate the performance. The inlet and outlet pressure of refrigerant for each of the component is also necessary to find out their enthalpy at corresponding state. The pressure transducer was fitted at the inlet and outlet of the compressor and expansion valve as shown in Fig. The pressure transducers were fitted with the $\mathrm{T}$-joint and then brazed with the tube to measure the pressure at desired position. The range of pressure transducer is -1 to +39 bars. The pressure transducers have also been interfaced with computer via data logger to store data. A service port was installed at the inlet of expansion valve and compressor for charging and recovering the refrigerant. A power meter was connected with compressor to measure the power and energy consumption. The resulting chemical reaction often produces pitting and other damage on the valves seals, bearing journal, cylinder wall and other polished surface of the system. It may cause the deterioration of the lubricating oil and the formation of sludge that can gum up valves, clog oil passages, score bearing surface and produce other effect that reduce the life of the system. Moisture in the system may exist in solution or as free water. Free water can freeze into the ice crystals inside the metering device and in the evaporator tubes of system that operate below the freezing point of the water. This reaction is called freeze up. When freeze up occurs, the formation of ice within the orifice of the metering device temporarily stops the flow of the liquid refrigerant.

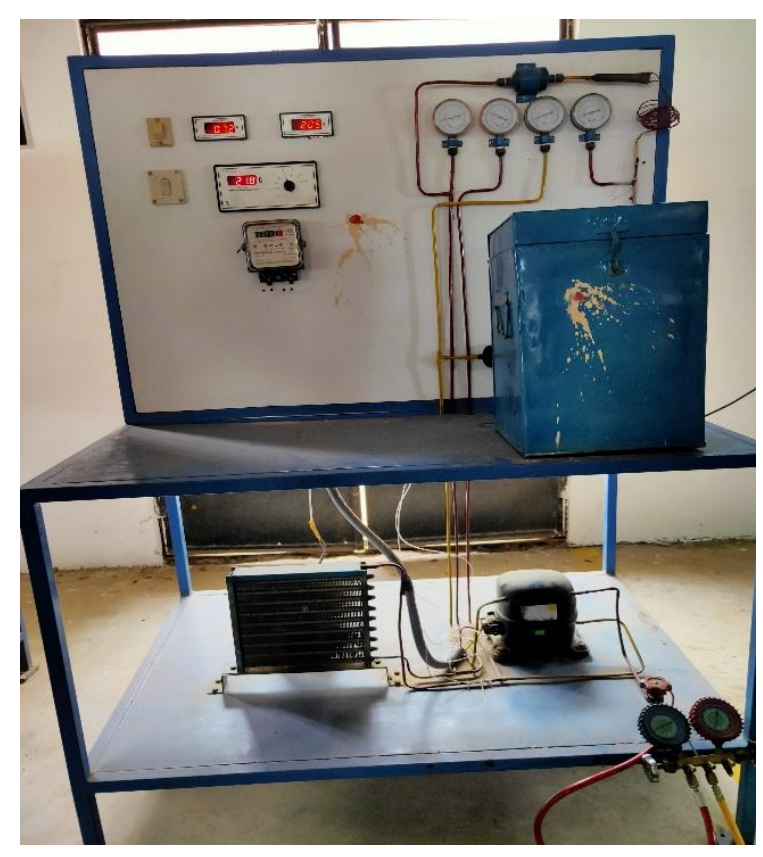

Figure 1 experimental setup 


\section{Results and Discussion}

In this section, the all COP of the three refrigerants after the calculation taken and plotted On the graph. The all refrigerants are using various electricity in the refrigeration process. According to the graph based the best COP of the refrigerant is considered for the alternative refrigerant

\section{Comparison of Actual COP's}

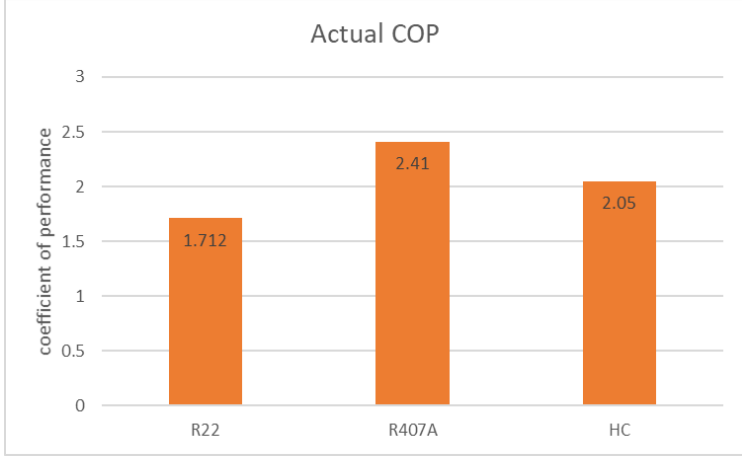

Figure 2 comparison of actual cop

In this section, the actual COP of the three refrigerants after the calculation taken and plotted On the graph. The best COP is considered for the alternative refrigerant. according to the best COP is given by $\mathrm{R} 407 \mathrm{~A}$.

\section{Comparison of Experimental COP's}

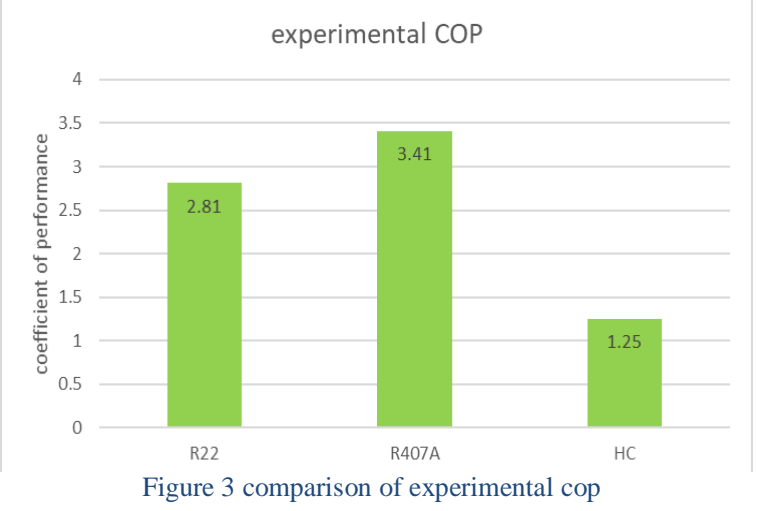

In this section, the actual COP of the three refrigerants after the calculation taken and plotted On the graph. The best COP is considered for the alternative refrigerant. according to the best COP is given by R407A.

\section{Comparison of Relative COP's}

In this section, the actual COP of the three refrigerants after the calculation taken and plotted On the graph. The best COP is considered for the alternative refrigerant. according to the best COP is given by $\mathrm{HC}$.

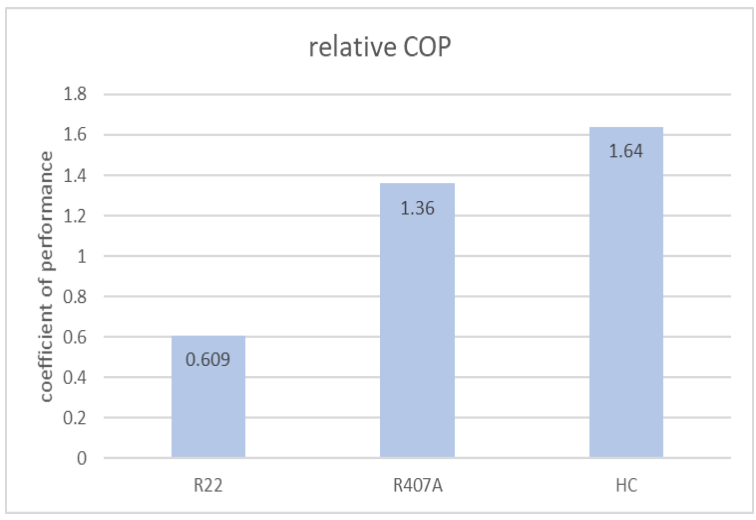

Figure 4 comparison of relative cop

\section{Conclusion}

$\mathrm{R} 407 \mathrm{~A}$ is have a good actual and experimental cop compare to other two refrigerants. But Hydro carbons have a good Global Warming Potential compare to other two refrigerants. Hydrocarbons and R407A are have non-ozone depletion compare to $\mathrm{R} 22$. The Hydro carbons energy consumption is less compare to R22, R407A. Hydro carbons using low electricity for cooling process compare to R22, R407A.

\section{Acknowledgments}

The author would like to thank the Principal Dr Sujatha Jamuna Anand and Head Of the Department Mechanical engineering Dr V Balaji of Loyola institute of technology Chennai for their kind support and encouragement to carry out this project work.

\section{Reference}

[1] D A Didion and D B Bivens, Role of refrigerant mixtures as alternatives to CFCs, Int. J. Refrig., Vol.13, No.5, pp.163-175, 1990

[2] Filippo de Rossi, R Mastrullo, Working fluids Thermodynamic Behaviour for Vapor Compression Cycles, Applied Energy, Vol.38, pp.163-180, 1991.

[3] L R Oellrich and S Srinivasa Murthy, Alternatives to CFCs for Refrigeration Applications, Scientific Series of the International Bureau, Vol.25, KFA, Juelich, (1994).

[4] S Vijayaraghavan Chakravarthy, Ramesh K Shah, and G Venkatarathnam, A Review of Refrigeration Methods in the Temperature Range 4-300 K, ASME J. Thermal Sci. Eng. Appl., Vol.3, pp.1-19, (2011). 